\title{
Performance of the CoughAssist Insufflation-Exsufflation Device in the Presence of an Endotracheal Tube or Tracheostomy Tube: A Bench Study
}

\author{
Claude Guérin MD PhD, Gaël Bourdin MD, Véronique Leray MD, Bertrand Delannoy MD, \\ Frédérique Bayle MD, Michèle Germain MD, and Jean-Christophe Richard MD PhD
}

\begin{abstract}
BACKGROUND: The CoughAssist is a mechanical insufflator-exsufflator designed to assist airway secretion clearance in patients with ineffective cough. The device may benefit intubated and tracheotomized patients. We assessed the impact of various artificial airways on peak expiratory flow (PEF) with the CoughAssist. METHODS: We measured PEF and pressure at the airway opening in a lung model during insufflation-exsufflation with the CoughAssist, at 3 set pressures: 30/-30, 40/-40, and 50/-50 cm $\mathrm{H}_{2} \mathrm{O}$, first without (control), and then with different sizes (6.5 to $8.5 \mathrm{~mm}$ inner diameter) of endotracheal tube (ETT) and tracheostomy tube $(6,7$, and $8 \mathrm{~mm}$ inner diameter), compliance settings of 30 and $60 \mathrm{~mL} / \mathrm{cm} \mathrm{H}_{2} \mathrm{O}$, and resistance settings of 0 and $5 \mathrm{~cm} \mathrm{H}_{2} \mathrm{O} / \mathrm{L} / \mathrm{s}$ ). We analyzed the relationship between PEF and pressure with linear regression. RESULTS: With compliance of $30 \mathrm{~mL} / \mathrm{cm} \mathrm{H}_{2} \mathrm{O}$ and 0 resistance the slope of the control relationship between PEF and pressure was statistically significantly greater than during any conditions with ETT or tracheostomy tube. Therefore, in comparison to the control, the relationship of PEF to pressure significantly went in the direction from top to bottom as the ETT or tracheostomy tube became narrower. The findings were the same with compliance of $30 \mathrm{~mL} / \mathrm{cm} \mathrm{H}_{2} \mathrm{O}$ and resistance of $5 \mathrm{~cm} \mathrm{H}_{2} \mathrm{O}$ / $\mathrm{L} / \mathrm{s}$. With compliance of $60 \mathrm{~mL} / \mathrm{cm} \mathrm{H}_{2} \mathrm{O}$ the highest set pressure values were not achieved and some relationships departed from linearity. The control slope of the relationship between PEF and pressure with compliance of $60 \mathrm{~mL} / \mathrm{cm} \mathrm{H}_{2} \mathrm{O}$ and 0 resistance did not significantly differ with any ETT or tracheostomy tube. CONCLUSIONS. The artificial airways significantly reduced PEF during insufflation-exsufflation with CoughAssist; the narrower the inner diameter of the artificial airway, the lower the PEF for a given expiratory pressure. Key words: insufflator-exsufflator; airway secretion clearance; cough; mechanical ventilation; intubation; tracheostomy; airways; peak expiratory flow; PEF; endotracheal tube. [Respir Care 2011;56(8):1108-1114. (C) 2011 Daedalus Enterprises]
\end{abstract}

\section{Introduction}

Cough efficacy is a main determinant of successful extubation, morbidity, and mortality in intensive care unit pa-

The authors are affiliated with Service de Réanimation Médicale et d'Assistance Respiratoire, Hôpital de la Croix Rousse, Lyon, France.

The authors have disclosed a relationship with Philips, Respironics, France, which provided the CoughAssist device.

Correspondence: Claude Guerin MD PhD, Service de Réanimation Médicale et d'Assistance Respiratoire, Hôpital de la Croix Rousse, 103 Grande Rue de la Croix Rousse, 69004 Lyon, France. E-mail: claude.guerin@ chu-lyon.fr.

DOI: $10.4187 /$ respcare. 01121 tients. ${ }^{1}$ Expiratory flow is an important determinant of airway secretion clearance. Cough can be impaired in patients with neuromuscular weakness, the main cause of which is critical illness neuromyopathy. ${ }^{2}$ Therefore, methods to improve cough efficacy are important because they facilitate weaning from

See the Related Editorial on Page 1217

mechanical ventilation and improve patient outcomes. Cough augmentation techniques require closure of the glottis prior to the cough, and invasive tubes do not allow glottal closure. However, high expiratory flow is still a determinant of passive mucus expulsion in the presence of tracheal tubes. 
Mechanical insufflation-exsufflation improves airway secretion clearance in patients with neuromuscular disease receiving noninvasive ventilation, ${ }^{3-6}$ and insufflation-exsufflation increases peak cough flow more than other cough enhancement methods. ${ }^{7}$

In intensive care unit patients receiving invasive mechanical ventilation, the endotracheal tube (ETT) or tracheostomy tube hinders insufflation-exsufflation by substantially increasing resistance to air flow. The narrower the inner diameter of the ETT or tracheostomy tube, the greater the flow resistance.

To our knowledge, there have been no studies on the impact of ETT or tracheostomy tube on insufflation-exsufflation. In a bench study we investigated the effect of various sizes of ETT and tracheostomy tube on the peak expiratory flow (PEF) during insufflation-exsufflation. We hypothesized that insufflation-exsufflation PEF would be impaired by artificial airways and that the extent of the impairment would depend on the size of the ETT or tracheostomy tube.

\section{Methods}

\section{Equipment}

The setup included a new CoughAssist (Respironics France, Carquefou, France) that was fully checked by the manufacturer prior to the present investigation; a 2-compartment test lung (Training and Test Lung, Michigan Instruments, Grand Rapids, Michigan) with adjustable compliance and parabolic resistors that mimic airway resistance; a pneumotachograph (Fleish 4, Fleish, Lausanne, Switzerland) and its data-acquisition system, a straight connector (VBM Medizintechnik, Sulz, Germany) to measure pressure at the airway opening $\left(\mathrm{P}_{\mathrm{ao}}\right)$; new ETTs (Hi-Lo, Mallinckrodt, Athlone, Ireland) (inner diameters of 6.5, 7.0, 7.5, 8.0, and $8.5 \mathrm{~mm}$ ); and new tracheostomy tubes (Mallinckrodt, Athlone, Ireland) (inner diameters of 6.0, $7.0,8.0 \mathrm{~mm}$ ). The pneumotachograph's measurements were linear in the flow range -10 to $10 \mathrm{~L} / \mathrm{s}$. The $\mathrm{P}_{\mathrm{ao}}$ port was connected to piezoresistive transducers (BD Gabarith, Vogt Medical Vertrieb, Karlsruhe, Germany). The signal was amplified, sent to an analog/digital converter (MP150, Biopac Systems, Goleta, California), and recorded at $200 \mathrm{~Hz}$ (Acqknowledge, Biopac Systems, Goleta, California).

\section{Protocol}

The experiments were performed in our pulmonary function test laboratory, at room temperature and in room air. Before the experiments the piezoresistive transducers were calibrated with a rotameter flow meter (Martin Médical, Lyon, France) for flow, and with a manometer (Companion, Puritan Bennett, Indianapolis, Indiana) for $\mathrm{P}_{\mathrm{ao}}$.
We tested 4 sets of lung mechanics conditions, in a random order, with each ETT or tracheostomy tube: compliance settings of $30 \mathrm{~mL} / \mathrm{cm} \mathrm{H}_{2} \mathrm{O}(\mathrm{C} 30)$ and $60 \mathrm{~mL} /$ $\mathrm{cm} \mathrm{H}_{2} \mathrm{O}(\mathrm{C} 60)$, and resistance settings of 0 (R0) and $5 \mathrm{~cm} \mathrm{H}_{2} \mathrm{O} / \mathrm{L} / \mathrm{s}$ (R5). For the R0 condition the resister was not attached to the setup. For each set of conditions we recorded a control condition in which the pneumotachograph and $\mathrm{P}_{\mathrm{ao}}$ port were directly attached to the test lung and no ETT or tracheostomy tube or resister was inserted into the test lung.

Insufflation and exsufflation were triggered automatically at the highest inspiratory flow, with an inspiratory/ expiratory ratio of $3 / 1$, and a 1 -second pause between expiration and inspiration. We tested inspiratory/expiratory pressures of $30 /-30,40 /-40$, and $50 /-50 \mathrm{~cm} \mathrm{H}_{2} \mathrm{O}$, in that order, for each condition.

We performed at least 5 insufflations and exsufflations in each condition (Fig. 1). Once recording was stable, we recorded the last 5 respiratory cycles for the analysis. The change in lung volume was calculated with the numerical integration of the flow signal.

\section{Data Analysis}

The experiments involved 108 combinations (4 mechanical conditions $\times 9$ control and artificial airways $\times 3$ set pressures). With 5 repetitions of each condition there were 540 measurements. The combinations were entirely independent of each other. We decided to analyze each of the 4 conditions separately. The main outcome measure was PEF. We assumed that the measured expiratory maximum $\mathrm{P}_{\mathrm{a}}$ might differ from the corresponding set pressure, so our analysis focused on the linear relationship between PEF and expiratory maximum $\mathrm{P}_{\mathrm{ao}}$. The primary outcome was the slope, and the secondary outcome was the intercept of the relationship between PEF (on the Y axis) and maximum $\mathrm{P}_{\mathrm{ao}}$ (on the $\mathrm{X}$ axis). Basically, PEF should increase with increasing $\mathrm{P}_{\mathrm{ao}}$. Since the $\mathrm{P}_{\mathrm{ao}}$ values on the $\mathrm{X}$ axis are negative, any increase in PEF with more negative values of $\mathrm{P}_{a}$ will result in a negative slope for a given artificial airway. The intercept is the value of $\mathrm{PEF}$ extrapolated back to a maximum $\mathrm{P}_{\mathrm{ao}}$ of 0 . The slope and intercept were obtained with a linear model, which also showed how PEF varied with maximum expiratory $\mathrm{P}_{\mathrm{ao}}$ under the fixed effect of an ETT or tracheostomy tube.

Each ETT or tracheostomy tube relationship was compared to the control condition. A reduction in the slope between the control and any given artificial airway means a lower increase in PEF for the same amount of change in $\mathrm{P}_{\mathrm{ao}}$ with that artificial airway, which results in a less negative slope. This finding is expected with any increase in resistance, as it occurs with the reduction in the inner diameter of the artificial airway. The comparison of 2 regression lines is done as follows. If the 2 regression lines 

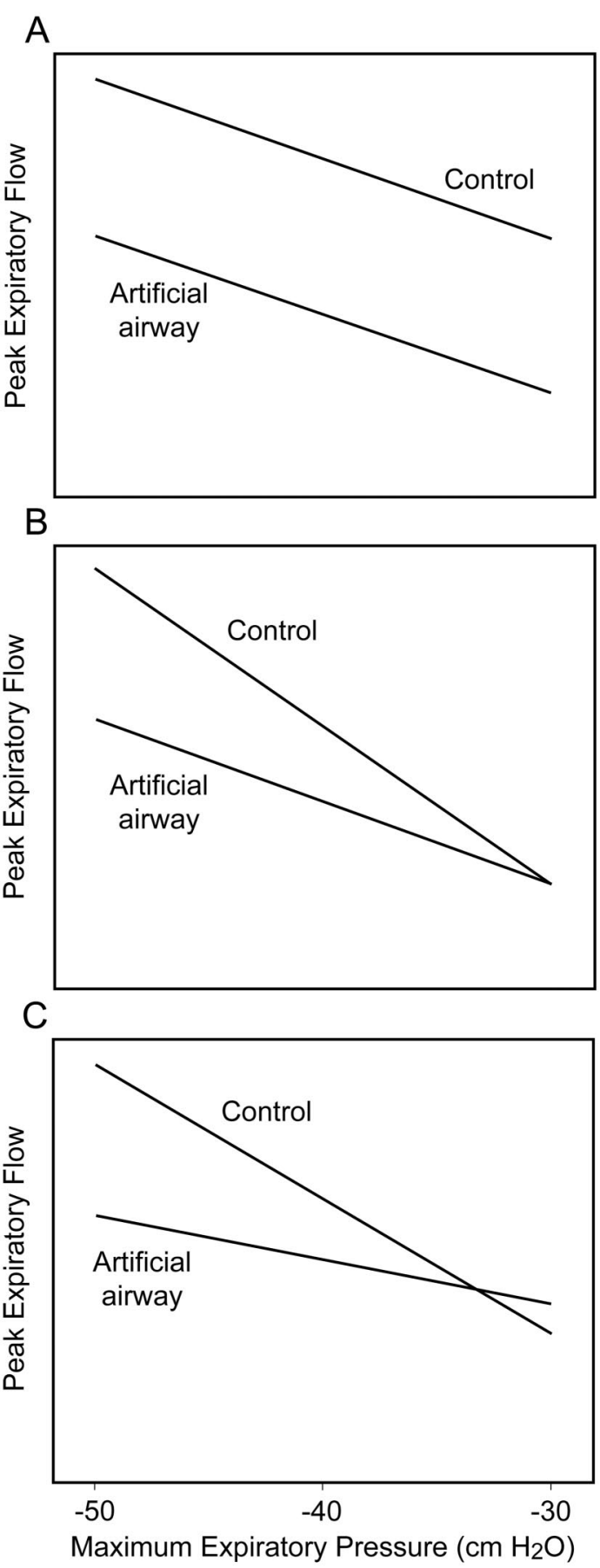

Fig. 1. Schematic graphs of regression lines fitted between peak expiratory flow and maximum expiratory pressure at the airway opening with the control setup and with an artificial airway. A: Parallel lines with equal slopes and unequal intercepts. B: Unequal slopes and equal intercepts. C: Unequal slopes and unequal intercepts.

(the control line and the artificial airway line) are parallel, as in Fig. 1A, there is a reduction in both the slope and the intercept with the artificial airway, as compared to control.
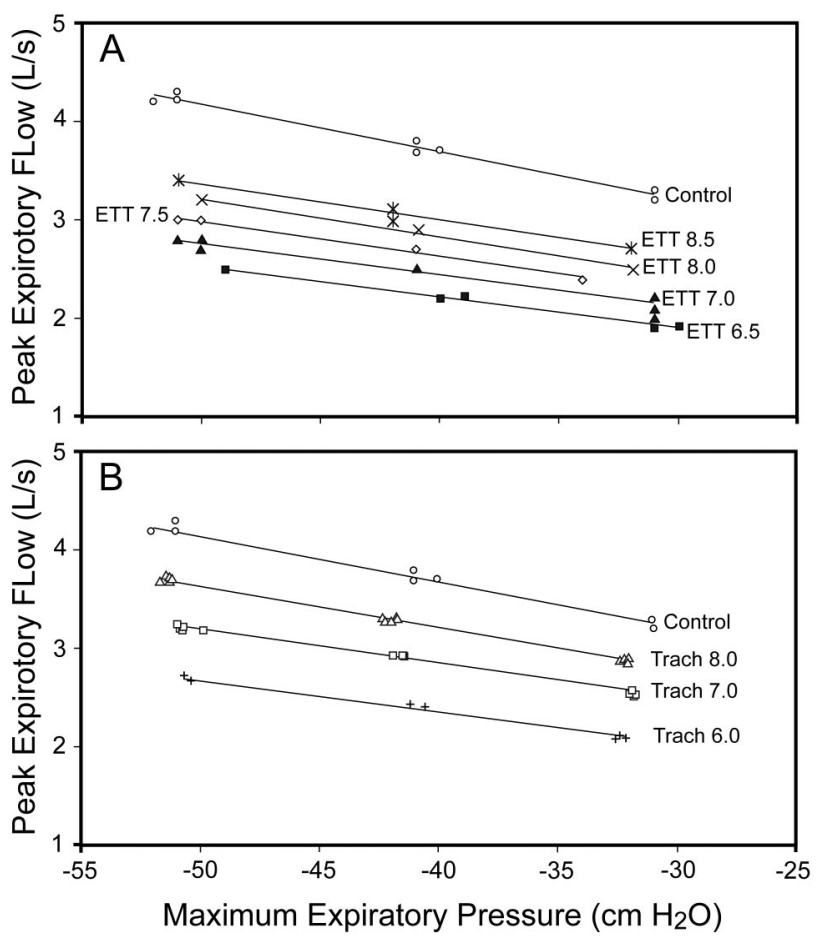

Fig. 2. Regression analysis of the relationship of peak expiratory flow to maximum expiratory pressure with set compliance of $30 \mathrm{~mL} /$ $\mathrm{cm} \mathrm{H}_{2} \mathrm{O}$ and 0 added resistance, with (A) 5 sizes of endotracheal tube (ETT) and (B) 3 sizes of tracheostomy tube (Trach). We made 5 measurements in each condition.

That means that the control has a consistently higher PEF than the artificial airway, but that the rate of change with respect to $P_{a o}$ is the same between them. If the 2 regression lines have different slopes (the control line has a greater slope) but a common intercept, as in Fig. 1B, that means that the control and artificial airway start with the same PEF but PEF changes with respect to $\mathrm{P}_{\mathrm{ao}}$ at a higher rate with the control than with the artificial airway. If the 2 regression lines have different slopes and different intercepts, as in Fig. 1C, the 2 curves intersect, which means that the relationships between PEF and $\mathrm{P}_{\mathrm{a}}$ are different between the control and the artificial airway.

The slope and intercept values are expressed as mean and $95 \%$ CI. The correlation coefficient (r) was used in the regression analysis. The analysis was carried out with statistics software (R 2.9.0, R Foundation for Statistical Computing, Vienna, Austria). $P<.05$ was set as the threshold for statistical significance.

\section{Results}

The relationships between PEF and maximum $\mathrm{P}_{\mathrm{ao}}$ were linear with all the ETTs and tracheostomy tubes (Fig. 2). The control slope was significantly greater (ie, more neg- 
Table 1. Intercept and Slope of the Relationships Between Peak Expiratory Flow and Pressure at the Airway Opening With Compliance Set at $30 \mathrm{~mL} / \mathrm{cm} \mathrm{H}_{2} \mathrm{O}$ and No Added Resistance

\begin{tabular}{|c|c|c|c|c|}
\hline & \multicolumn{2}{|c|}{ Intercept $(\mathrm{L} / \mathrm{s})$} & \multicolumn{2}{|c|}{ Slope $\left(\mathrm{cm} \mathrm{H}_{2} \mathrm{O} / \mathrm{L} / \mathrm{s}\right)$} \\
\hline & Mean & $95 \% \mathrm{CI}$ & Mean & $95 \% \mathrm{CI}$ \\
\hline Control & 1.763 & 1.566 to 1.960 & -0.048 & -0.053 to -0.0 \\
\hline \multicolumn{5}{|c|}{ Endotracheal Tube } \\
\hline $6.5 \mathrm{~mm}$ & $0.924 *$ & 0.629 to 1.219 & $-0.032^{*}$ & -0.039 to -0.025 \\
\hline $7.0 \mathrm{~mm}$ & $1.149^{*}$ & 0.855 to 1.442 & $-0.032 *$ & -0.039 to -0.025 \\
\hline $7.5 \mathrm{~mm}$ & $1.202 *$ & 0.855 to 1.548 & $-0.036^{*}$ & -0.044 to -0.028 \\
\hline $8.0 \mathrm{~mm}$ & $1.272 *$ & 0.957 to 1.587 & $-0.039 *$ & -0.046 to -0.031 \\
\hline $8.5 \mathrm{~mm}$ & $1.524 *$ & 1.220 to 1.828 & $-0.037^{*}$ & -0.044 to -0.030 \\
\hline \multicolumn{5}{|c|}{ Tracheostomy Tube } \\
\hline $6.0 \mathrm{~mm}$ & $1.153^{*}$ & 0.839 to 1.467 & $-0.030^{*}$ & -0.038 to -0.023 \\
\hline $7.0 \mathrm{~mm}$ & $1.455^{*}$ & 1.150 to 1.759 & $-0.035^{*}$ & -0.042 to -0.028 \\
\hline $8.0 \mathrm{~mm}$ & $1.582 *$ & 1.281 to 1.883 & $-0.041^{*}$ & -0.048 to -0.034 \\
\hline
\end{tabular}

$* P<.001$ vs control for all differences.

ative) than that of any ETT or tracheostomy tube (Table 1). The same was true for the intercept. Thus, the ETT or tracheostomy tube shifted the relationships of PEF to maximum $\mathrm{P}_{\text {ao }}$ down, in comparison with control. Furthermore, the smaller the inner diameter of the artificial airway, the lower the PEF for a given maximum $\mathrm{P}_{\mathrm{ao}}$ (see Fig. 2).

The relationships between PEF and maximum $\mathrm{P}_{\text {ao }}$ were linear for each ETT and tracheostomy tube (data not shown). The control slope was statistically significantly greater (ie, more negative) than the control except for the $7.5-\mathrm{mm}$ ETT (Table 2). The control intercept was significantly greater than with every ETT or tracheostomy tube (see Table 2). There were similar downwards shifts from the control in the relationships between PEF and maximum $\mathrm{P}_{\mathrm{ao}}$ with the narrowing of the ETT or tracheostomy tube (data not shown).

The relationships between PEF and maximum $\mathrm{P}_{\mathrm{ao}}$ were non-linear with the 7.5-mm ETT (Fig. 3). The control slope for the relationship between PEF and maximum $\mathrm{P}_{\mathrm{a}}$ did not differ with any ETT or tracheostomy tube (Table 3). The control intercept was significantly greater than that with all except the 7.5-mm ETT (see Table 3).

The relationships between PEF and maximum $\mathrm{P}_{\mathrm{ao}}$ were non-linear with the 8.0-mm ETT, the 8.5-mm ETT, and the 7.0-mm tracheostomy tube (Fig. 4). The control slope for the relationships between PEF and maximum $\mathrm{P}_{\mathrm{ao}}$ was significantly lower (ie, less negative) with the $7.5-\mathrm{mm}$ ETT and significantly higher (ie, more negative) with the 6.0-mm tracheostomy tube (Table 4). The control intercept was significantly higher than with the $6.5-\mathrm{mm}$ ETT, the 7.5-mm ETT, the 6-mm tracheostomy tube, or the 8-mm tracheostomy tube (see Table 4).
Table 2. Intercept and Slope of the Relationships Between Peak Expiratory Flow and Pressure at the Airway Opening With Compliance Set at $30 \mathrm{~mL} / \mathrm{cm} \mathrm{H}_{2} \mathrm{O}$ and Resistance Set at $5 \mathrm{~cm} \mathrm{H} \mathrm{H}_{2} \mathrm{O} / \mathrm{L} / \mathrm{s}$

\begin{tabular}{|c|c|c|c|c|}
\hline & \multicolumn{2}{|c|}{ Intercept (L/s) } & \multicolumn{2}{|c|}{ Slope $\left(\mathrm{cm} \mathrm{H}_{2} \mathrm{O} / \mathrm{L} / \mathrm{s}\right)$} \\
\hline & Mean & $95 \% \mathrm{CI}$ & Mean & $95 \% \mathrm{CI}$ \\
\hline Control & 1.596 & 0.434 to 1.758 & -0.037 & -0.041 to -0.033 \\
\hline \multicolumn{5}{|c|}{ Endotracheal Tube } \\
\hline $6.5 \mathrm{~mm}$ & $0.893 *$ & 0.679 to 1.107 & $-0.029 *$ & -0.035 to -0.024 \\
\hline $7.0 \mathrm{~mm}$ & $1.163 *$ & 0.934 to 1.392 & $-0.027 *$ & -0.033 to -0.022 \\
\hline $7.5 \mathrm{~mm}$ & $0.806^{*}$ & 0.572 to 1.039 & -0.039 & -0.045 to -0.033 \\
\hline $8.0 \mathrm{~mm}$ & $1.457 *$ & 1.243 to 1.670 & $-0.030 *$ & -0.035 to -0.025 \\
\hline $8.5 \mathrm{~mm}$ & $1.392 *$ & 1.168 to 1.616 & $-0.032 *$ & -0.037 to -0.026 \\
\hline \multicolumn{5}{|c|}{ Tracheostomy Tube } \\
\hline $6.0 \mathrm{~mm}$ & $1.072 *$ & 0.844 to 1.301 & $-0.029 *$ & -0.034 to -0.023 \\
\hline $7.0 \mathrm{~mm}$ & $1.254 *$ & 1.035 to 1.473 & $-0.033^{*}$ & -0.038 to -0.027 \\
\hline $8.0 \mathrm{~mm}$ & $1.420 *$ & 1.196 to 1.645 & $-0.035^{*}$ & -0.040 to -0.030 \\
\hline
\end{tabular}
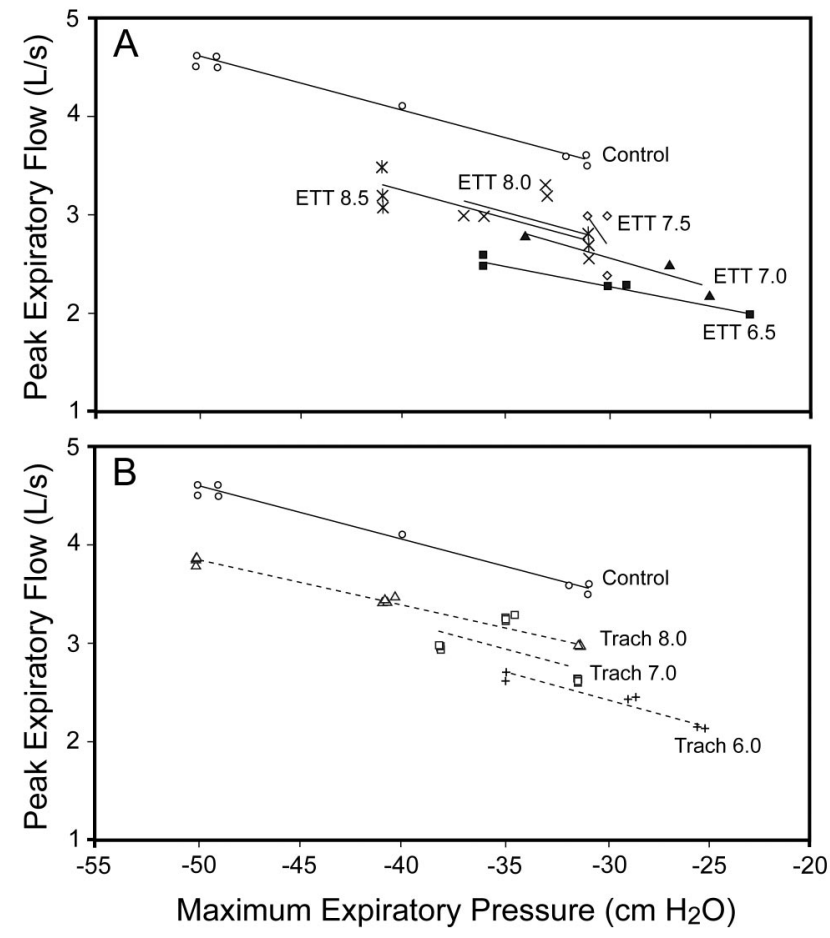

Fig. 3. Regression analysis of the relationship of peak expiratory flow to maximum expiratory pressure with set compliance of $60 \mathrm{~mL} /$ $\mathrm{cm} \mathrm{H}_{2} \mathrm{O}$ and 0 added resistance, with (A) 5 sizes of endotracheal tube (ETT) and (B) 3 sizes of tracheostomy tube (Trach). We made 5 measurements in each condition.

\section{Discussion}

PEF during insufflation-exsufflation with the CoughAssist was reduced by the ETTs and tracheostomy tubes. 
Table 3. Intercept and Slope of the Relationships Between Peak Expiratory Flow and Pressure at the Airway Opening With Compliance Set at $60 \mathrm{~mL} / \mathrm{cm} \mathrm{H}_{2} \mathrm{O}$ and No Added Resistance

\begin{tabular}{|c|c|c|c|c|}
\hline & \multicolumn{2}{|c|}{ Intercept (L/s) } & \multicolumn{2}{|c|}{ Slope $\left(\mathrm{cm} \mathrm{H}_{2} \mathrm{O} / \mathrm{L} / \mathrm{s}\right)$} \\
\hline & Mean & $95 \% \mathrm{CI}$ & Mean & $95 \% \mathrm{CI}$ \\
\hline Control & 1.869 & 1.648 to 2.090 & -0.055 & -0.060 to -0.049 \\
\hline \multicolumn{5}{|c|}{ Endotracheal Tube } \\
\hline $6.5 \mathrm{~mm}$ & $1.090 *$ & 0.775 to 1.404 & -0.040 & -0.050 to -0.030 \\
\hline $7.0 \mathrm{~mm}$ & $0.767 *$ & 0.351 to 1.184 & -0.060 & -0.075 to -0.046 \\
\hline $7.5 \mathrm{~mm} \dagger$ & -6.299 & -9.876 to -2.723 & -0.054 & -0.078 to -0.030 \\
\hline $8.0 \mathrm{~mm}$ & $1.131 *$ & 0.330 to 1.931 & -0.056 & -0.068 to -0.044 \\
\hline $8.5 \mathrm{~mm}$ & $1.024 *$ & 0.576 to 1.472 & -0.054 & -0.068 to -0.040 \\
\hline \multicolumn{5}{|c|}{ Tracheostomy Tube } \\
\hline $6.0 \mathrm{~mm}$ & $0.829 *$ & 0.403 to 1.255 & -0.054 & -0.075 to -0.034 \\
\hline $7.0 \mathrm{~mm}$ & $1.061 *$ & 0.348 to 1.774 & -0.047 & -0.054 to -0.039 \\
\hline $8.0 \mathrm{~mm}$ & $1.539^{*}$ & 1.236 to 1.841 & -0.046 & -0.054 to -0.039 \\
\hline
\end{tabular}
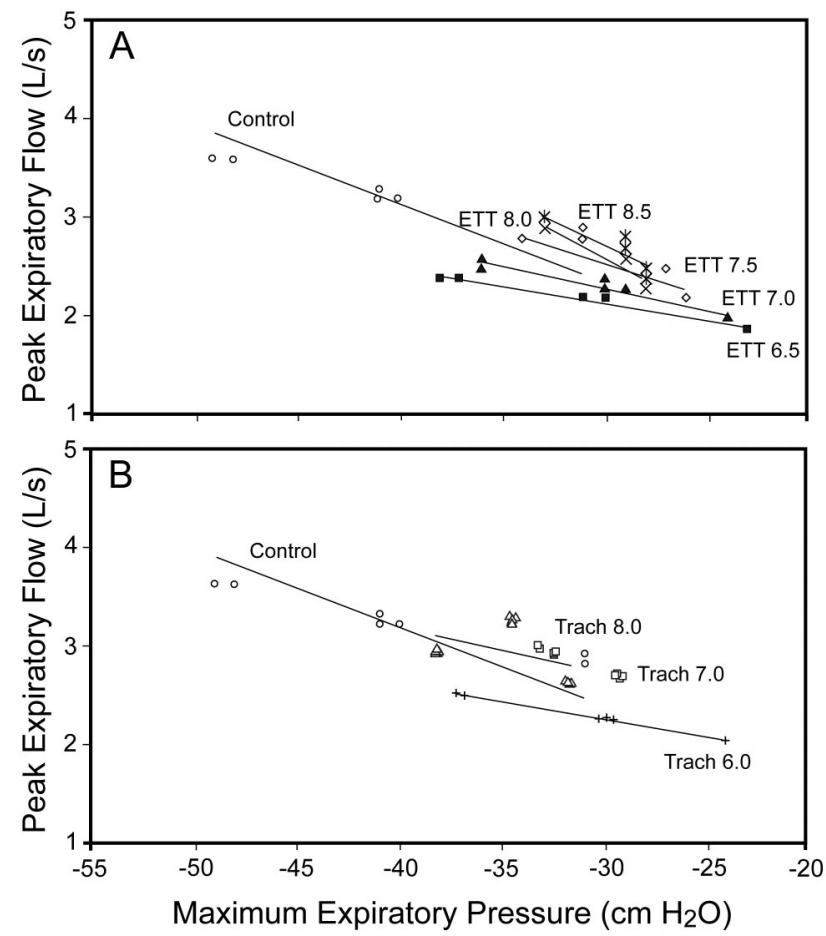

Fig. 4. Regression analysis of the relationship of peak expiratory flow to maximum expiratory pressure with set compliance of $30 \mathrm{~mL}$ $\mathrm{cm} \mathrm{H}_{2} \mathrm{O}$ and set resistance of $5 \mathrm{~cm} \mathrm{H}_{2} \mathrm{O} / \mathrm{L} / \mathrm{s}$, with (A) 5 sizes of endotracheal tube (ETT) and (B) 3 sizes of tracheostomy tube (Trach). We made 5 measurements in each condition.

Although this result is expected, as acknowledged in the manufacturer's specifications, this is the first systematic in vitro assessment of the performance of the CoughAssist in the presence of artificial airways.
Table 4. Intercept and Slope of the Relationships Between Peak Expiratory Flow and Pressure at the Airway Opening With Compliance Set at $60 \mathrm{~mL} / \mathrm{cm} \mathrm{H}_{2} \mathrm{O}$ and Resistance Set at $5 \mathrm{~cm} \mathrm{H}_{2} \mathrm{O} / \mathrm{L} / \mathrm{s}$

\begin{tabular}{|c|c|c|c|c|}
\hline & \multicolumn{2}{|c|}{ Intercept (L/s) } & \multicolumn{2}{|c|}{ Slope $\left(\mathrm{cm} \mathrm{H}_{2} \mathrm{O} / \mathrm{L} / \mathrm{s}\right)$} \\
\hline & Mean & $95 \% \mathrm{CI}$ & Mean & $95 \% \mathrm{CI}$ \\
\hline Control & 1.512 & 1.349 to 1.676 & -0.043 & -0.047 to -0.039 \\
\hline \multicolumn{5}{|c|}{ Endotracheal Tube } \\
\hline $6.5 \mathrm{~mm}$ & $1.119^{*}$ & 0.903 to 1.335 & -0.035 & -0.042 to -0.028 \\
\hline $7.0 \mathrm{~mm}$ & $0.951^{*}$ & 0.697 to 1.205 & -0.045 & -0.053 to -0.036 \\
\hline $7.5 \mathrm{~mm}$ & $0.558^{*}$ & 0.208 to 0.907 & $-0.067 *$ & -0.078 to -0.055 \\
\hline $8.0 \mathrm{~mm} \dagger$ & -0.736 & -1.310 to -0.162 & -0.111 & -0.131 to -0.092 \\
\hline $8.5 \mathrm{~mm}^{\dagger}$ & -65.320 & -78.850 to -51.789 & -2.200 & -2.637 to -1.762 \\
\hline \multicolumn{5}{|c|}{ Tracheostomy Tube } \\
\hline $6.0 \mathrm{~mm}$ & $1.146^{*}$ & 0.905 to 1.387 & $-0.037 *$ & -0.044 to -0.029 \\
\hline $7.0 \mathrm{~mm}^{\dagger}$ & -1.151 & -1.869 to -0.434 & -0.125 & -0.148 to -0.101 \\
\hline $8.0 \mathrm{~mm}$ & $1.405^{*}$ & 0.859 to 1.952 & -0.044 & -0.059 to -0.028 \\
\hline
\end{tabular}

\section{Effects of Artificial Airways on Peak Flow During Exsufflation}

It has been recognized for some time that artificial airways increase airway resistance, ${ }^{8,9}$ so greater pressure is required to generate a given air flow. Therefore, breathing spontaneously through an artificial airway induces a specific work of breathing. ${ }^{10}$ The normal cough function is expected to be impaired by an artificial airway, by increasing the airway resistance and thus reducing the expiratory flow, and by preventing glottis closure and thus reducing the cough pressure. In 8 healthy volunteers intubated with a 8.0-mm ETT, in whom maximum voluntary coughing was initiated after inspiration to total lung capacity, the maximum cough pressure and total volume expelled were similar to the control values, but the flow was significantly lower than control. ${ }^{11}$ Thus, tracheal intubation does not impair pressure, despite preventing glottic closure. The effect of the CoughAssist was not assessed in those subjects. In intubated patients a spontaneous cough PEF threshold value of $1 \mathrm{~L} / \mathrm{s}$ was consistently found to predict extubation failure. ${ }^{1,12}$ Again, the effect of CoughAssist was not assessed in those patients. In tracheally intubated and mechanically ventilated patients with neuromuscular diseases, much higher assisted PEF threshold values predicted extubation failure, ${ }^{13}$ as discussed below. Before assessing in vivo the performance of the CoughAssist in intubated patients, and given the lack of systematic data in this field, we decided to carry out this bench study to investigate the effects of artificial airways on PEF generated by this device at different lung compliance and resistance. 
Performance of the CoughAssist Insufflation-Exsufflation Device

Table 5. Expected Expiratory Pressure* to Reach Assisted Peak Expiratory Flow of 2.7 L/s Computed With the Constants in Tables 1 Through 4

\begin{tabular}{|c|c|c|c|c|}
\hline & $\begin{array}{c}\text { Compliance } 30 \mathrm{~mL} / \mathrm{cm} \mathrm{H}_{2} \mathrm{O} \\
\text { Resistance } 0 \mathrm{~cm} \mathrm{H} \mathrm{H}_{2} \mathrm{O} / \mathrm{L} / \mathrm{s}\end{array}$ & $\begin{array}{c}\text { Compliance } 30 \mathrm{~mL} / \mathrm{cm} \mathrm{H}_{2} \mathrm{O} \\
\text { Resistance } 5 \mathrm{~cm} \mathrm{H}_{2} \mathrm{O} / \mathrm{L} / \mathrm{s}\end{array}$ & $\begin{array}{c}\text { Compliance } 60 \mathrm{~mL} / \mathrm{cm} \mathrm{H}_{2} \mathrm{O} \\
\text { Resistance } 0 \mathrm{~cm} \mathrm{H} \mathrm{H}_{2} \mathrm{O} / \mathrm{L} / \mathrm{s}\end{array}$ & $\begin{array}{c}\text { Compliance } 60 \mathrm{~mL} / \mathrm{cm} \mathrm{H}_{2} \mathrm{O} \\
\text { Resistance } 5 \mathrm{~cm} \mathrm{H}_{2} \mathrm{O} / \mathrm{L} / \mathrm{s} \\
\end{array}$ \\
\hline Control & $20(17-22)$ & $30(28-56)$ & $15(12-17)$ & $28(27-29)$ \\
\hline \multicolumn{5}{|c|}{ Endotracheal Tube } \\
\hline $6.5 \mathrm{~mm}$ & $55(52-60)$ & $61(58-66)$ & $40(38-44)$ & $46(43-49)$ \\
\hline $7.0 \mathrm{~mm}$ & $48(47-50)$ & $57(54-61)$ & $32(31-33)$ & $39(38-41)$ \\
\hline $7.5 \mathrm{~mm}$ & $42(42-42)$ & $49(48-50)$ & $\mathrm{NA} \dagger$ & $32(32-33)$ \\
\hline $8.0 \mathrm{~mm}$ & $37(36-38)$ & $41(41-41)$ & $28(17-35)$ & $\mathrm{NA} \dagger$ \\
\hline $8.5 \mathrm{~mm}$ & $32(29-34)$ & $41(41-42)$ & $31(31-31)$ & $\mathrm{NA} \dagger$ \\
\hline \multicolumn{5}{|c|}{ Tracheostomy Tube } \\
\hline $6.0 \mathrm{~mm}$ & $51(49-54)$ & $57(54-60)$ & $34(31-43)$ & $42(40-45)$ \\
\hline $7.0 \mathrm{~mm}$ & $35(34-37)$ & $44(44-45)$ & $35(24-44)$ & $\mathrm{NA} \dagger$ \\
\hline $8.0 \mathrm{~mm}$ & $27(24-29)$ & $37(36-37)$ & $25(22-27)$ & $30(27-31)$ \\
\hline
\end{tabular}

\section{Comparison of Present Results to Other Bench Studies}

An increase in resistance is expected to decrease the $\mathrm{PEF}$ produced by an insufflation-exsufflation device. In vitro, Sancho et $\mathrm{al}^{14}$ found that the PEF generated by CoughAssist averaged 3.51, 2.52, and 2.24 L/s with resistances of 6,11 , and $17 \mathrm{~cm} \mathrm{H}_{2} \mathrm{O} / \mathrm{L} / \mathrm{s}$, respectively, at a set expiratory pressure of $-40 \mathrm{~cm} \mathrm{H}_{2} \mathrm{O}$ and a set compliance of $25 \mathrm{~mL} / \mathrm{cm} \mathrm{H}_{2} \mathrm{O}$, which would correspond to a $36 \% \mathrm{PEF}$ reduction between resistances of 6 and $17 \mathrm{~cm} \mathrm{H}_{2} \mathrm{O} / \mathrm{L} / \mathrm{s}$. This PEF reduction was close to that obtained between the 6.5-mm ETT and the control with our C30/R5 condition at $-40 \mathrm{~cm} \mathrm{H}_{2} \mathrm{O}$ (see Table 1). By computing the averaged linear relationship of $\mathrm{PEF}$ and $\mathrm{P}_{\mathrm{ao}}$ for the C25/R6 condition from the data in Table 2 of the Sancho et al study, ${ }^{14}$ the slope found is $-0.038 \mathrm{~cm} \mathrm{H}_{2} \mathrm{O} / \mathrm{L} / \mathrm{s}$ and the intercept is $1.866 \mathrm{~L} / \mathrm{s}$. Interestingly, these values, and in particular the slope, were very close to those found for the control condition in the present experiment (data not shown). However, when the process is repeated for C25/R11, the slope is steeper $\left(-0.0497 \mathrm{~cm} \mathrm{H} \mathrm{H}_{2} \mathrm{O} / \mathrm{L} / \mathrm{s}\right)$ and the intercept is $0.379 \mathrm{~L} / \mathrm{s}$, whereas for $\mathrm{C} 25 / \mathrm{R} 17$ the slope is $0.022 \mathrm{~cm} \mathrm{H}_{2} \mathrm{O}$ / $\mathrm{L} / \mathrm{s}$ and the intercept is $1.303 \mathrm{~L} / \mathrm{s}$, which corresponds to our finding with the 6.5-mm ETT. Even though these computations are approximations, they indicate that the present data are consistent with previous measurements with a lung model with the same device.

\section{Clinical Implications}

A specific weaning protocol that includes predetermined criteria for the extubation of neuromuscular patients was recently reported. ${ }^{13}$ It notably included assisted cough peak flow of $\geq 160 \mathrm{~L} / \mathrm{min}$ (ie, $\geq 2.66 \mathrm{~L} / \mathrm{s}$ ) as an extubation criterion. Furthermore, the protocol included post-extubation noninvasive ventilation in volume-cycled mode and aggressive machine-assisted coughing. ${ }^{13}$ The protocol was applied to 157 consecutive "unweanable" neuromuscular patients. The first-attempt protocol extubation success rate was $95 \%$. Moreover, extubation was successful in all 98 attempts in patients whose assisted cough peak flow was $\geq 2.66 \mathrm{~L} / \mathrm{s}$ while still intubated. This result is in line with a previous report that suggested that this threshold for assisted cough peak flow may be useful in predicting successful extubation in neuromuscular patients. ${ }^{15}$ Therefore, the insufflation-exsufflation device should aim to achieve cough peak flow above $2.66 \mathrm{~L} / \mathrm{s}$. In a previous in vitro experiment in which any additional artificial airways were inserted into the lung model, this threshold was reached whenever the set inspiratory/expiratory pressures were $\geq-30 / 30 \mathrm{~cm} \mathrm{H}_{2} \mathrm{O}$ with compliance of $50 \mathrm{~mL} / \mathrm{cm} \mathrm{H}_{2} \mathrm{O}$ and resistance of $6 \mathrm{~cm} \mathrm{H} \mathrm{H}_{2} \mathrm{O} / \mathrm{L} / \mathrm{s}$. ${ }^{16}$ Table 5 shows the set expiratory pressure to generate an assisted $\mathrm{PEF}$ of $2.66 \mathrm{~L} / \mathrm{s}$ under the various conditions, based on the linear regression parameters in Tables 1 through 4 of the present study. As expected, greater pressure is required as the inner diameter of the artificial airway or lung compliance decreases. Table 5 suggests that pressures of 40/-40 or even 50/$50 \mathrm{~cm} \mathrm{H}_{2} \mathrm{O}$ should be used in patients receiving invasive mechanical ventilation, though this requires in vivo confirmation.

\section{Limitations}

The main limitation of the present study is that it was in vitro, so the results cannot be extrapolated to the in vivo condition. It is well known that the flow resistance of artificial airways in vitro largely underestimates that 


\section{Performance of the CoughAssist Insufflation-Exsufflation Device}

in vivo, ${ }^{17}$ for several reasons, including kinking and accumulated secretions. Given that the present results show that artificial airways significantly decrease CoughAssist's performance, and given that the resistance imposed by an artificial airway is underestimated in vitro, the performance of CoughAssist in patients receiving invasive mechanical ventilation should be investigated.

We stress that, although CoughAssist is used in intubated and tracheotomized patients, clinicians must take care to avoid accumulation of expelled secretions in the ventilator circuit and inside or at the distal end of the artificial airway. Suctioning should always be part of the treatment with CoughAssist.

\section{Conclusions}

Artificial airways significantly reduced PEF with the CoughAssist. To achieve the desired PEF in patients with artificial airways, the set pressure should be increased. This result may have clinical implications in intensive care medicine.

\section{REFERENCES}

1. Smina M, Salam A, Khamiees M, Gada P, Amoateng-Adjepong Y, Manthous CA. Cough peak flows and extubation outcomes. Chest 2003;124(1):262-268.

2. De Jonghe B, Sharshar T, Lefaucheur JP, Authier FJ, Durand-Zaleski I, Boussarsar M, et al. Paresis acquired in the intensive care unit: a prospective multicenter study. JAMA 2002;288(22):28592867.

3. Miller RG, Rosenberg JA, Gelinas DF, Mitsumoto H, Newman D, Sufit R, et al. Practice parameter: the care of the patient with amyotrophic lateral sclerosis (an evidence-based review): report of the Quality Standards Subcommittee of the American Academy of Neurology: ALS Practice Parameters Task Force. Neurology 1999;52(7): 1311-1323.
4. Vianello A, Corrado A, Arcaro G, Gallan F, Ori C, Minuzzo M, et al. Mechanical insufflation-exsufflation improves outcomes for neuromuscular disease patients with respiratory tract infections. Am J Phys Med Rehabil 2005;84(2):83-88, discussion 89-91.

5. Chatwin M, Simonds AK. The addition of mechanical insufflation/ exsufflation shortens airway-clearance sessions in neuromuscular patients with chest infection. Respir Care 2009;54(11):1473-1479.

6. Homnick DN. Mechanical insufflation-exsufflation for airway mucus clearance. Respir Care 2007;52(10):1296-1305, discussion 13061307.

7. Chatwin M, Ross E, Hart N, Nickol AH, Polkey MI, Simonds AK. Cough augmentation with mechanical insufflation/exsufflation in patients with neuromuscular weakness. Eur Respir J 2003;21(3):502508 .

8. Nunn JF. Applied respiratory physiology. London: Butterworths; 1987.

9. Gal TJ, Suratt PM. Resistance to breathing in healthy subjects following endotracheal intubation under topical anesthesia. Anesth Analg 1980;59(4):270-274.

10. Shapiro M, Wilson RK, Casar G, Bloom K, Teague RB. Work of breathing through different sized endotracheal tubes. Crit Care Med 1986;14(12):1028-1031.

11. Gal TJ. Effects of endotracheal intubation on normal cough performance. Anesthesiology 1980;52(4):324-329.

12. Su WL, Chen YH, Chen CW, Yang SH, Su CL, Perng WC, et al Involuntary cough strength and extubation outcomes for patients in an ICU. Chest 2010;137(4):777-782.

13. Bach JR, Goncalves MR, Hamdani I, Winck JC. Extubation of patients with neuromuscular weakness: a new management paradigm. Chest 2010;137(5):1033-1039.

14. Sancho J, Servera E, Marin J, Vergara P, Belda FJ, Bach JR. Effect of lung mechanics on mechanically assisted flows and volumes. Am J Phys Med Rehabil 2004;83(9):698-703.

15. Bach JR, Ishikawa Y, Kim H. Prevention of pulmonary morbidity for patients with Duchenne muscular dystrophy. Chest 1997;112(4): 1024-1028.

16. Gomez-Merino E, Sancho J, Marin J, Servera E, Blasco ML, Belda FJ, et al. Mechanical insufflation-exsufflation: pressure, volume, and flow relationships and the adequacy of the manufacturer's guidelines. Am J Phys Med Rehabil 2002;81(8):579-583.

17. Wright PE, Marini JJ, Bernard GR. In vitro versus in vivo comparison of endotracheal tube airflow resistance. Am Rev Respir Dis 1989;140(1):10-16.

This article is approved for Continuing Respiratory Care Education credit. For information and to obtain your CRCE

(free to AARC members) visit

www.RCJournal.com

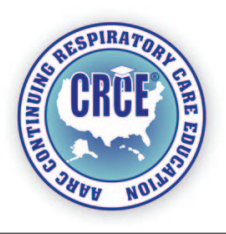

